\title{
Irrigation with low quality water: model approach
}

\author{
A. Refsgaard \& M. Styczen \\ DHI - Water and Environment, Horsholm, Denmark
}

\begin{abstract}
Limited availability of good quality water increases the need for a strategy for the use of wastewater and other low quality waters for various purposes. Irrigation with low quality water may affect crop quality, crop production and the environment.

In the EU-project "SAFIR" (www.safir4eu.org) the "open modelling interface" (openMI-protocol) for model interaction is being used to integrate modelling tools handling all issues within irrigation management on a farm level, i.e. water sources, water purification, soil-plant-atmosphere processes, irrigation and fertigation strategy, risk assessment, crop quality and economy. The integrated modelling system will be used as the core of a decision support system to select water sources for irrigation and define purification requirements, based on the demands to crop quality and yield as well as economic issues. Short term and long term effects on concentrations of pollutants affecting crop quality are thoroughly analysed to propose improved practices and determine critical concentration levels. The accumulation of pollutants within a single crop cycle and the long term deterioration and degradation of the root zone of the soil will also be addressed.

The integrated modelling system will be tested on data from a comprehensive field investigation programme in Denmark, Italy, Greece, Romania and China. Keywords: irrigation, low quality water, decision support system, modelling.
\end{abstract}

\section{Introduction}

A huge amount of the fresh water resources of the world are used to irrigate crops. However, in many places around the world, clean water is a scarce resource, and waste water, treated or untreated, is used as water source for 
irrigation. The result may be contamination of the crop and/or the soil, or risks to farm workers working with the dirty water.

Different strategies may be employed to reduce the problem. First of all, water saving methods of irrigation, such as e.g. partial root drying (PRD), may be used to minimize the water use. Secondly, the dirty water may be used for irrigation only during crop stages, where it does not cause problems or it may be diluted with water from a better source during critical growing periods to ensure that any contamination is kept below critical levels.

Tools for such analyses have been developed for different purposes, e.g. to describe the solute fluxes between the water source (river or well) and applied irrigation water at field level, to describe plant growth as a function of water and nutrient availability or to describe plant uptake of pollutants. However, new irrigation techniques and the relationships between water quality and crop quality, require further development of tools and descriptions.

The decision support system planned must help the irrigation manager on a farm determine which water source and irrigation method to use, taking into account the water quality, water purification possibilities, and water quantity available, as well as the quality of the final produce. It is the vision of the system planned that the project manager is able to compare irrigation methods, water use, water sources and purification techniques with respect to economic return (taking into account crop quality) as well as risks to farm workers, consumers and soil and groundwater resources. With the tool is should be possible to prevent that acceptable limits are exceeded.

The immediate target group of the system is well educated farmers and agricultural extensionists. For specific sites with a given water quality, it may be possible to extract simpler rules from model runs.

The system is planned to work on "a number of fields with different crops", but in the SAFIR project, all components will be developed only for tomatoes and potatoes.

\section{The decision support system}

The framework of the decision support system to be developed and tested in the SAFIR project is shown in fig. 1. More specifically, the system should be able to answer a number of specific questions, such as

\section{For single fields (scenario mode):}

a. Taking into account the present crop history, if we irrigate using this technique and with water from this source, what is the effect on yield, risks and economy, assuming that

I. we continue with the same source until harvest, or

II. continue with clean water until harvest, or

III. do not irrigate further.

b. Taking into account the present crop history, what is the difference on crop quality, risks and economy if I use water from source A and source $\mathrm{B}$ for the rest of the season? 
c. What will be projected water use and benefits/risk if I change to a different irrigation method?

\section{For multiple fields (scenario mode):}

d. With the existing constraints of water, how will my total water use be distributed for a given crop distribution, irrigation technology and set of crop prices?

\section{Multiple fields (forecast mode):}

e. With the existing constraints of water and the present selection of water, what is the proposed irrigation and fertigation strategy for the forecast period, e.g. 5 days?

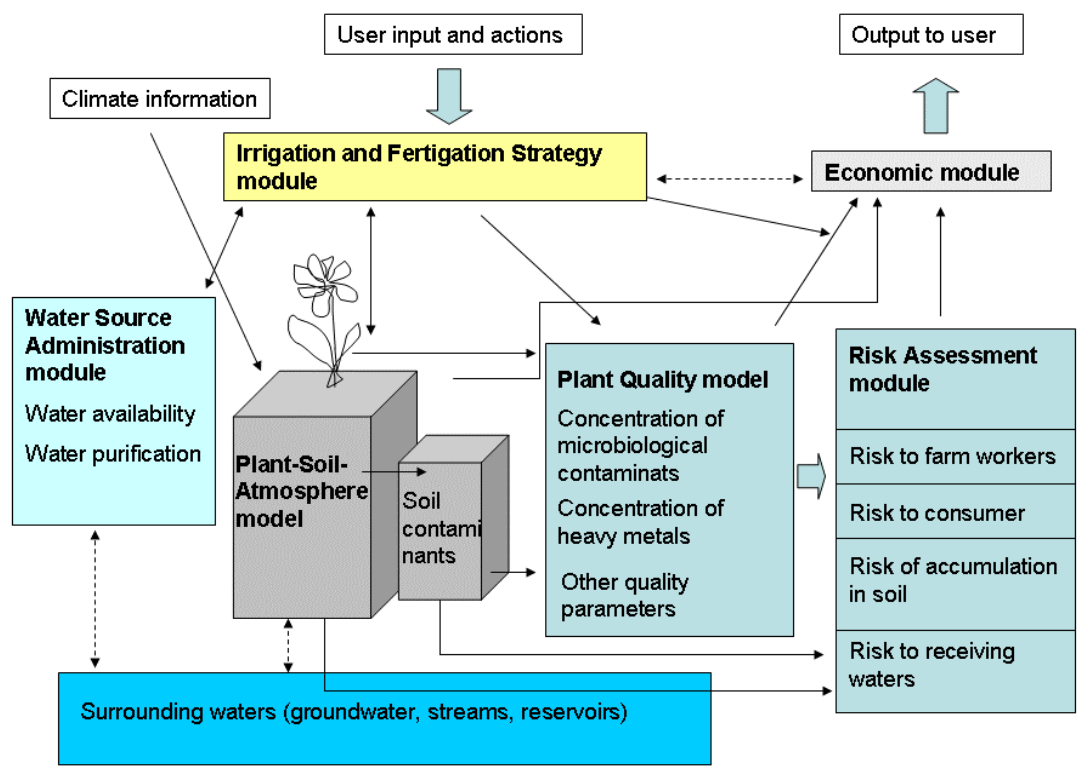

Figure 1: Overview of the models and modules in the management model.

In principle, there will be early stages of irrigation projects, where water quality simulations could help to choose the right irrigation system, filtering methods, disinfection, irrigation management etc. When an irrigation system is established and the growing season has begun, the actual number of realistic choices is much reduced.

The key elements in the irrigation management system are the Irrigation and Fertigation Strategy module and the Plant-Soil-Atmosphere model (PSA-model). The PSA-model calculates the irrigation water demand and the crop yield. It supplies key information for calculation of impact on the production system and quality of the final produce using the various quality waters as well as risks for 
the food chain (from field to fork). The PSA-model must be set up at the latest at the beginning of the growing season and the model is updated regularly during the growing season. To answer the questions above, it must be possible to run scenarios from the last endpoint, to choose a strategy and to update the simulation with the actually implemented strategy.

The irrigation and fertigation strategies are governed from the Irrigation and Fertigation Strategy module, which allows the user to specify irrigation criteria and rules for irrigation and fertigation. The module interacts with the PSA-model and other modules to determine a possible strategy to follow in a given situation.

As indicated the system consists of:

1) a Plant-Soil-Atmosphere model,

2) an Irrigation and Fertigation Strategy module,

3) a Water Source Administration module,

4) a Plant Quality model,

5) a Risk Assessment module, and

6) an Economic module.

Calculations related to soil contaminants may be collected in a specific module or be part of the plant quality and the risk assessment modules. The modules and models interact with climatic information and surrounding waters and receive input from the user of the system as well as give suggestions to the user.

The modules are expected to be communicating through OpenMI-interfaces, a system developed in an earlier in an EU-project (Gijsbers [1]). The OpenMItechnology is a very promising tool for linking of models originally conceived with different purposes (Westen et al. [2]). However, so far the experience with the technology is limited to rather few cases. An important point is therefore to tailor the OpenMI standard to field and farm scale modelling, to make a step-bystep procedure for implementation of the modelling interface and to test it on software relevant for irrigation management. The OpenMI-system supports models in .NET-languages and the advantage of using OpenMI is that all modules in the system can be exchanged with other modules performing the same task - as long as they are wrapped to exchange the same data. In the following a short description of the DSS modules and models is given.

\subsection{The Plant-Soil-Atmosphere model}

In the first version of the management model the Plant-Soil-Atmosphere model will be the Daisy model (Hansen et al. [3], Abrahamsen and Hansen [4]), which is a well-validated soil-plant-atmosphere system modelling framework that simulates all main components of the water and nitrogen cycle in 1D. A new water saving irrigation concept - partial root drying (PRD) - is tested in the project. Partial root drying means that different parts of the root zone are alternately wetted, causing an uneven moisture distribution in the root zone. Daisy is currently being developed to account for two-dimensional effects related 
to the PRD. Daisy requires basically a description of the soil (horizons, hydraulic properties, textural information, bulk density, organic content, C/N-relationship), a description of the climate (and already performed irrigation) from initialization of the simulation till present (precipitation, insolation, average temperature, wind speed, vapour pressure or alternatively reference evaporation), and management (crop, sowing time, tillage, fertilization).

Climate and weather time series will have to be administered through the user interface for the different types of runs. It is anticipated that three different options will be possible:

1) actual weather in the year to be simulated,

2) forecasts of e.g. 5 days, and

3) historical climatic series.

In relation to the management model Daisy will also handle concentrations of nitrate and ammonia, be able to describe the irrigation methods, and handle the lower boundary condition, such as groundwater level. The PSA-model works in close contact with the Irrigation and Fertigation Strategy module. When the PSA-model has developed a water and N-demand, the Irrigation and Fertigation Strategy module then governs the actions to be taken with respect to irrigation and fertigation based on the conditions in the soil and plant, and the water availability and quality. This information is transferred or iterated with other modules and models in the management model. In order to create an overview of the system, an input/output matrix is developed for each of the models and modules in the system. The draft input and output matrix for the Plant-SoilAtmosphere model is shown in Table 1.

\subsection{The Irrigation and Fertigation Strategy module}

The PSA-model interacts closely with the Irrigation and Fertigation Strategy module that tells the plant/soil model about the irrigation conditions (date, depth, how much water and content of ammonia and nitrate).

This module will specify an irrigation strategy only if the PSA-model registers stress with respect to either water or $\mathrm{N}$ for at least one simulated field in a forecast period - or when running a historical weather series. The module will:

1) estimate whether irrigation is required for each field,

2) estimate whether fertigation is required for each field,

3) estimate whether the required amount and quality of water is available,

4) make some sort of economic assessment of whether irrigation is economically defendable,

5) and schedule the required irrigation, i.e. tell the PSA-model how much water is required for how long on which date and with which content of ammonia and nitrate,

6) calculate the input of other compounds with the irrigation water and list it in a tabular form. 
Table 1: $\quad$ Draft input and output matrix for the PSA-model.

\begin{tabular}{|c|c|c|c|}
\hline Input & From & Unit & $\begin{array}{l}\text { Data } \\
\text { type }\end{array}$ \\
\hline $\begin{array}{l}\text { Irrigation water: } \\
-\quad \text { quantity of water and } \\
-\quad \text { concentration of nitrate and } \\
\text { ammonia }\end{array}$ & $\begin{array}{lr}\text { Irrigation } & \text { and } \\
\text { Fertigation } & \text { Strategy } \\
\text { module } & \end{array}$ & $\begin{array}{l}\mathrm{m}^{3} \mathrm{~m}^{-2} \mathrm{~s}^{-1} \\
\mathrm{~g} \mathrm{\textrm {m } ^ { - 3 }}\end{array}$ & $\begin{array}{l}\text { Time } \\
\text { series }\end{array}$ \\
\hline $\begin{array}{l}\text { Lower boundary condition, such as } \\
\text { groundwater level and concentration } \\
\text { if required }\end{array}$ & $\begin{array}{l}\text { "Surrounding } \\
\text { Waters*" }\end{array}$ & $\mathrm{m}$ & $\begin{array}{l}\text { Time } \\
\text { series }\end{array}$ \\
\hline Output & To & Unit & $\begin{array}{l}\text { Data } \\
\text { type }\end{array}$ \\
\hline $\begin{array}{l}\text { Indicators of water demand and N- } \\
\text { demand }\end{array}$ & $\begin{array}{lr}\text { Irrigation } & \text { and } \\
\text { Fertigation } & \text { Strategy } \\
\text { module } & \\
\end{array}$ & $\mathrm{m}^{3}$ & $\begin{array}{l}\text { Time } \\
\text { series }\end{array}$ \\
\hline $\begin{array}{l}\text { Percolation to groundwater: } \\
-\quad \text { quantity of water and } \\
-\quad \text { concentration of nitrate and } \\
\text { ammonia }\end{array}$ & $\begin{array}{l}\text { "Surrounding } \\
\text { Waters*" module } \\
\text { and Risk Assessment } \\
\text { module }\end{array}$ & $\begin{array}{l}\mathrm{m}^{3} \mathrm{~m}^{-2} \mathrm{~s}^{-1} \\
\mathrm{~g} \mathrm{~m}^{-3}\end{array}$ & $\begin{array}{l}\text { Time } \\
\text { series }\end{array}$ \\
\hline $\begin{array}{l}\text { Drainwater losses: } \\
-\quad \text { quantity of water and } \\
-\quad \text { concentration of nitrate and } \\
\text { ammonia }\end{array}$ & $\begin{array}{l}\text { "Surrounding } \\
\text { Waters*" and Risk } \\
\text { Assessment module }\end{array}$ & $\begin{array}{l}\mathrm{m}^{3} \mathrm{~s}^{-1} \\
\mathrm{~g} \mathrm{~m}^{-3}\end{array}$ & $\begin{array}{l}\text { Time } \\
\text { series }\end{array}$ \\
\hline $\begin{array}{l}\text { Crop stage, development stage, crop } \\
\text { type }\end{array}$ & $\begin{array}{lr}\text { Irrigation } & \text { and } \\
\text { Fertigation Strategy } \\
\text { module and Plant } \\
\text { Quality model }\end{array}$ & - & $\begin{array}{l}\text { Time } \\
\text { series }\end{array}$ \\
\hline $\begin{array}{l}\text { Harvested dry matter } \\
\text { Harvested C } \\
\text { Harvested N, } \\
\text { (Uptake of xenobiotics) }\end{array}$ & $\begin{array}{l}\text { Economic model } \\
\text { Plant Quality model } \\
\text { Plant Quality model } \\
\text { Plant Quality model } \\
\end{array}$ & $\begin{array}{l}\mathrm{Kg} \mathrm{ha}^{-1} \\
\mathrm{Kg} \mathrm{ha}^{-1} \\
\mathrm{Kg} \mathrm{ha}^{-1} \\
?\end{array}$ & $\begin{array}{l}\text { Time } \\
\text { series }\end{array}$ \\
\hline $\begin{array}{l}\text { Water balance components (to be } \\
\text { defined) }\end{array}$ & Plant Quality model & Pending & $\begin{array}{l}\text { Time } \\
\text { series }\end{array}$ \\
\hline $\begin{array}{l}\text { Concentration of nitrate, ammonia } \\
\text { and additional compound in the soil }\end{array}$ & $\begin{array}{l}\text { Risk Assessment } \\
\text { module }\end{array}$ & $\begin{array}{l}\mathrm{g} \mathrm{m}^{-3} \text { or } \\
\mathrm{g} \mathrm{kg}^{-1}\end{array}$ & $\begin{array}{l}\text { Values at } \\
\text { different } \\
\text { depths }\end{array}$ \\
\hline
\end{tabular}

* "Surrounding waters" may be described by time series, by models or may in some cases not be accounted for.

The module has to operate differently depending on whether a scenario run is performed or whether it is a forecast.

In case of a scenario run, the PSA-models describing the different fields on the irrigated farm may develop a deficit of water and $\mathrm{N}$, and the module has to respond with respect to water and fertigation on the basis of water ability and an economic indicator that gives preference for particular fields. The final plant quality and yield is not known at the time when the Irrigation and fertigation strategy module allocates the water. 
In case of a forecast, the situation is different. The PSA-model can simulate the case with and without irrigation in the forecast period and a with a selected irrigation strategy for the following period until harvest. In this case simulated yield loss, quality parameters, risks and economy can be presented to the user together with proposed dates of irrigation that takes into account the actual water availability.

The Irrigation and Fertigation Strategy module mainly communicates with the PSA-model and the Water Sources Administration module but requires some economic information.

Important outputs of the module for a scenario run include:

1) a set of dates and irrigation amounts and irrigation depth for each field

2) an amount of fertigation with the irrigation water - fertigation is adjusted for inorganic $\mathrm{N}$ in the irrigation water,

3) a table of irrigation dates, method, water quantity, nutrient content and critical compounds added with irrigation water, to be used by other modules for further calculations.

Important outputs of the module for a forecast run include:

4) a proposed set of dates and irrigation amounts for each field specifically for the forecast period,

5) a proposed amount of fertigation with the irrigation water - fertigation is adjusted for inorganic $\mathrm{N}$ in the irrigation water,

6) together with the economics of the irrigation action based on simulations with the PSA-model and prices of the harvested crop, water and fertigation, and

7) a simple estimate of bacteriological risk (low, medium, high) for the specific application, based on the content in the irrigation water, the crop type, the DT50-value and the time till harvest may be included.

\subsection{The Water Source Administration module}

In the conceptual model, the water sources may be a river, a reservoir or a groundwater well. The system will be able to choose between at least two sources - that is to discard a source, if it turns out to be of too poor quality, or to dilute one, if the resulting quality becomes acceptable.

The water source may be described by a model or by a number of time series only. The content should, in case of a time series, be the maximum extractable amount of water and the quality of water defined by the concentration of NO3-, $\mathrm{NH}_{4}^{+}$, organic matter and other compounds of relevance. In the most complex mode such a module could consists of a groundwater model, a river model and a model of an irrigation reservoir including interaction between the models regarding both water quantity and quality. However, this is not foreseen within the scope of this project.

A water purification plant may - or may not- be assigned to a water source. If there is no purification plant, the water amount and quality that goes on to the 
next step is unchanged. If there is a water purification plant, it is suggested that the purification process must be defined by the fraction of water passing through the plant and the fraction of each pollutant passing through the plant.

The module will, when the irrigation and fertigation strategy module demands it, return how much water is available from each source, what the water quality of each source is and what is the mixing ratio to fulfil particular criteria. In some areas, water is only available on certain dates, and that is of course included in the water source files mentioned above. The capacity of the equipment may be a limiting factor for the water availability calculation.

The module thus takes into account the water availability of each source, the capacity of the equipment, the priority of water sources, purification of water from one or both sources and losses in the distribution system, losses caused by the choice of purification system and possibly one or more quality parameters that must be fulfilled.

The Irrigation and Fertigation Strategy module returns the actual amount of water used from each source, making it possible to calculate the actual extraction required.

\subsection{The Plant Quality module}

The Plant Quality module assesses the crop quality as a function of the irrigation water quality. The content of xenobiotics and heavy metals in the fruit may be assessed as well as the microbiological contamination on the fruit. Other quality parameters may be a function of water content and nutrient uptake. In reality, it thus consists of several rather independent assessments:

1) Assessment of microbiological contamination of fruit

2) Assessment of xenobiotics and heavy metals in the fruit

3) Assessment of other quality parameters in the fruit.

The biological contamination depends on irrigation technology, water quality and timing of irrigation and the placement of the harvested part of the crop. Special focus will be on the transfer of toxic solutes (heavy metals and As) to the food products and on long term effects related to their accumulation in soil and their potential transfer to groundwater (Kass et al. [5]). Assessment of this will require information on the total amount of contamination as well as of water balance elements, sorption properties and plant uptake parameters. Whether it will be possible to assess differences in crop quality parameters such as nutrients and sugar due to differences related to irrigation practise remains to be seen from the experimental results of the project.

\subsection{The Risk Assessment module}

The Risk Assessment module consists of four different more or less independent sub-models, which are used to assess risk due to:

1) direct exposure of the farm worker during cropping,

2) exposure to consumer when the crop is eaten, 
3) the risk for accumulation of unwanted compounds in the soil over one or more seasons, and

4) the risk of leaching of unwanted compounds to groundwater or via drain water to surface water.

The exposure of the farm worker mainly relates to biological contamination during cropping and harvest. The exposure to the consumer is mainly biological but could also be related to content of metals or organic contaminants.

The accumulation risk could be heavy metals or total ion content, while the leaching in addition can contain unwanted nutrients.

Some of the inputs to this module include irrigation method, irrigation water quality, amount of irrigation, concentration of microbiological contaminants on the crop at harvest, total uptake of xenobiotics and heavy metals as well as other quality parameters, concentrations of compounds in the soil and percolation to groundwater and drainage system. The result of the risk assessment is a table of risk indicators calculated with the different sub-models.

\subsection{The Economic module}

The Economic module will compare the cost of irrigation with the income from the harvested crop. The accumulated cost of water, purification and fertigation is calculated for each defined scenario, as well as the cost of other inputs. Crop yield is estimated with the given water quality and the price of the crop is determined based on crop quality.

\section{Conclusions}

The proposed management system is presently in the design phase. Partners of the different work packages of the SAFIR project co-operate to produce the final design, and the responsibility for building the different modules will be distributed to the relevant partners. The first prototype is expected in 2008 and will be tested on data from one of the field sites.

\section{References}

[1] Gijsbers, P. (2004). The openMI architecture - details. 6th International Conference on Hydroinformatics - Liong, Phoon \& Babovic (eds), World Scientific Publishing Company.

[2] Westen, S., Fortune, D., Gregersen, J. 2004. OpenMI - New Opportunities for Model Developers. 6th International Conference on Hydroinformatics - Liong, Phoon \& Babovic (eds), 2004 World Scientific Publishing Company.

[3] Hansen, S., H.E. Jensen, N.E. Nielsen and H. Svendsen 1991. Simulation of nitrogen dynamics and biomass production in winter wheat using the Danish simulation model DAISY. Fert. Res. 27: 245-259. 
266 Sustainable Irrigation Management, Technologies and Policies

[4] Abrahamsen, P., and Hansen, S. 2000. DAISY: An Open Soil-CropAtmosphere System Model. Environ. Model. Software 15, 313-330.

[5] Kass, A., Gavrielia, I., Yechielia, Y., Vengoshc, A. and. Starinskyb, A. 2005. The impact of freshwater and wastewater irrigation on the chemistry of shallow groundwater: a case study from the Israeli Coastal Aquifer. Journal of Hydrology 300, 314-331. 